\title{
Transcanal Endoscopic Tympanoplasty for Pediatric Patients Under 15 Years of Age With Chronic Otitis Media
}

\author{
Sungsu Lee (i) $\cdot$ Hyong-Ho Cho (i) \\ Department of Otolaryngology-Head and Neck Surgery, Chonnam National University Hospital, \\ Chonnam National University Medical School, Gwangju, Korea
}

Objectives. To evaluate the results of transcanal endoscopic tympanoplasty for pediatric patients with chronic otitis media $(\mathrm{COM})$ and compare them to that of the previously standard microscopic assisted tympanoplasty technique.

Methods. The patients were divided into two groups based on the operative method. Group 1 underwent tympanoplasty with a totally endoscopic assisted technique ( $\mathrm{n}=21,24$ ears), and group 2 underwent tympanoplasty with the conventional microscopic technique ( $\mathrm{n}=14,15$ ears). We used a transcanal approach in group 1 and a postauricular approach in group 2. In group 1 , there were 15 cases of simple COM and nine cases of adhesive otitis media. In group 2 , only 15 cases of simple COM were present. We analyzed the outcomes in terms of the hearing gain according to the surgical method and COM type, operation time, hospital stay after surgery, and graft success rate.

Results. Postoperative hearing gain results including air conduction (AC) thresholds and air-bone gap (ABG) were not significantly different between the two groups $(P>0.05)$. In both the groups, significant improvement in the postoperative $\mathrm{AC}$ and $\mathrm{ABG}$ was observed compared to the preoperative hearing. The hospital stay after surgery was significantly shorter in group 1 than the group 2: $2.1 \pm 0.4$ days and $4.8 \pm 0.9$ days $(P<0.001)$, respectively. The intact graft success rate was $91.6 \%$ in group 1 and $93 \%$ in group 2 ; the values were not significantly different $(P>0.05)$. There was neither intra- nor postoperative complications.

Conclusion. Transcanal endoscopic ear surgery technique is more conservative than microscopic approach and can be performed in pediatric patients under 15 years of age with COM. Moreover, it offers similar surgical results compared to traditional microscopic technique, and a shorter operative time and hospital stay after surgery are the advantages of this technique.

Keywords. Otitis Media; Tympanoplasty; Endoscopic Surgical Procedure; Child

\section{INTRODUCTION}

Surgical treatment of chronic otitis media (COM) has gloriously developed after the incorporation of the surgical microscopy in

\footnotetext{
- Received March 5, 2019

Revised May 7, 2019

Accepted June 26, 2019

- Corresponding author: Hyong-Ho Cho

Department of Otolaryngology-Head and Neck Surgery, Chonnam National University Hospital, Chonnam National University Medical School,

42 Jebong-ro, Dong-gu, Gwangiu 61469, Korea

Tel: +82-62-220-6776, Fax: +82-62-228-7743

E-mail: victocho@hanmail.net
}

the 1950s [1]. Most of the otolaryngologists still prefer surgery with the microscope. Middle ear surgery using endoscopy was initiated in the 1960s. Initially, surgeons who were more used to microscopic manipulation felt uncomfortable in avoiding the use of endoscopy. However, numerous reports have been published on the use of endoscopy and the interest and importance of the endoscopic middle ear surgery have been revealed [2-5].

In cases with pediatric COM, many surgeons prefer a postauricular approach due to the narrow external auditory canal (EAC). However, transcanal approach using endoscope provides many advantages including, visualizing more details with wider view, less invasive eradication of the disease, middle ear recon-

Copyright $\odot 2020$ by Korean Society of Otorhinolaryngology-Head and Neck Surgery

This is an open-access article distributed under the terms of the Creative Commons Attribution Non-Commercial License (https://creativecommons.org/licenses/by-nc/4.0)

which permits unrestricted non-commercial use, distribution, and reproduction in any medium, provided the original work is properly cited. 
struction, and capable operation with narrow EAC. It is hypothesized that in some way or either endoscopic surgery might substitute former microscopic operation [6,7]. Herein, we have investigated the results of endoscopic transcanal tympanoplasty in pediatric patients aged below 15 years and attempted to explore the benefits of the technique.

\section{MATERIALS AND METHODS}

\section{Operative instruments}

For pediatric surgery, usually, more slender and shorter endoscope is used compared to sinus endoscopic surgery. We mostly used endoscope measuring $0^{\circ}, 2.7 \mathrm{~mm}$ in diameter and $11-14 \mathrm{~cm}$ in length. The endoscope measuring $30^{\circ}, 3.0 \mathrm{~mm}$ in diameter, and $14 \mathrm{~cm}$ in length was used additionally if needed. Similar surgical instruments were used for the previous microscopic middle ear surgery.

\section{Subjects}

Pediatric patients under the age of 15 years who underwent type I tympanoplasty from November 2008 through August 2017 were enrolled in the study. All the operations were done by one surgeon (HHC). Patients were divided into two groups depending on the operative method. There were 21 subjects ( 24 ears, group 1) with the endoscopic transcanal approach and the remaining 14 subjects (15 ears, group 2) were with microscopic postauricular approach.

Mean age of group 1 patients was 10 years (4-15 years). Simple COM was 15 ears and adhesive otitis media were nine ears. The mean age of group 2 patients was 11 years (6-15 years) and all were simple COM. There were no significant differences in the size of the perforation between the two groups (Table 1). The study was approved by the Institutional Review Board of Chonnam National University Hospital (IRB No. CNUH-2019-060).

\section{H I G H L I G G H T S}

- When tympanoplasty is performed in pediatric patients, endoscopy provides a wider view compared to the conventional microscopy and enables the transcanal approach in pediatric patients with narrow external auditory canal.

- Improvements in postoperative air conduction and air-bone gap were compared between the endoscopic group and microscopic group, and no statistical significance was observed $(P>0.05)$.

- Compared the operation time between two groups, the endoscopic group showed statistically meaningful less operative duration $(P=0.002)$.

- Hospitalization duration was shorted in the endoscopic group $(P<0.001)$.
Table 1. Demographic characteristics of patients

\begin{tabular}{lccc}
\hline Variable & $\begin{array}{c}\text { Endoscopy } \\
\text { (group 1) }\end{array}$ & $\begin{array}{c}\text { Microscopy } \\
\text { (group 2) }\end{array}$ & Total \\
\hline No. of patients & 21 & 14 & 31 \\
Ear & 24 & 15 & 39 \\
Age (yr), mean (range) & $10(4-15)$ & $11(6-15)$ & $10.4(4-15)$ \\
Sex (male:female) & $16: 5$ & $7: 7$ & \\
Type of COM & & & \\
$\quad$ Simple (small: & 15 Ears (5:7:3) & 15 Ears (5:4:6) & 30 Ears (10:11:9) \\
$\quad$ moderate:large) & & & \\
$\quad$ Adhesive & 9 Ears & 0 & 9 Ears \\
Site (Rt:Lt:both) & $4: 14: 3$ & $7: 6: 1$ & $9: 19: 3$ \\
\hline
\end{tabular}

COM, chronic otitis media; Rt, right; Lt, left; TMSA, tympanic membrane surface area.

a)Tympanic membrane perforation size: small (<30\% TMSA), moderate (31\%-60\% TMSA), large (>60\% TMSA).

\section{Operation procedure}

For endoscopic surgery (group 1), general anesthesia was administered to 20 cases and local anesthesia to four cases. In all the cases, transcanal approach with $2 \%$ lidocaine and 1:100,000 epinephrine mixed solution injection on 3, 6, 9, and 12 o'clock position of the EAC was performed. Temporalis fascia harvest was done at $1 \mathrm{~cm}$ above the superior margin of the auricle. Cartilage and perichondrium were collected from the tragus. The endoscope was held by the left hand and surgical instruments were inserted by sliding by the EAC with the right hand. First, perforated tympanic membrane margin was trimmed with a sharp pick. EAC canal incision was done starting from 6 o'clock to the 12 o'clock position. EAC canalomeatal flap was elevated to gain entry into the tympanum. Pathologic lesion in the tympanum was checked and removed. Perforation was reconstructed with the harvested fascia and supported by gel foam (Fig. 1). In the case of tympanoplasty using the cartilage, the adhered tympanic membrane was separated from the promontory and then cartilage and perichondrium were placed underneath. In all the cases of microscopic surgeries (group 2), general anesthesia with conventional tympanoplasty with postauricular approach was administered except for two cases of near total perforation. In this cases, cartilage tympanoplasty was performed. (Table 2).

\section{Comparison of the postoperative results}

In order to investigate the utility of endoscopic transcanal tympanoplasty in pediatric patients, conventional microscopic surgery was set up as the control group. Postoperative hearing gain, postoperative hospitalization duration, and success of the tympanic membrane reconstruction were compared between the two groups. For statistical analysis, paired and independent $t$ test was performed by IBM SPSS ver. 19.0 (IBM Corp., Armonk, NY, USA). A $P<0.05$ was defined as statistically significant value. 

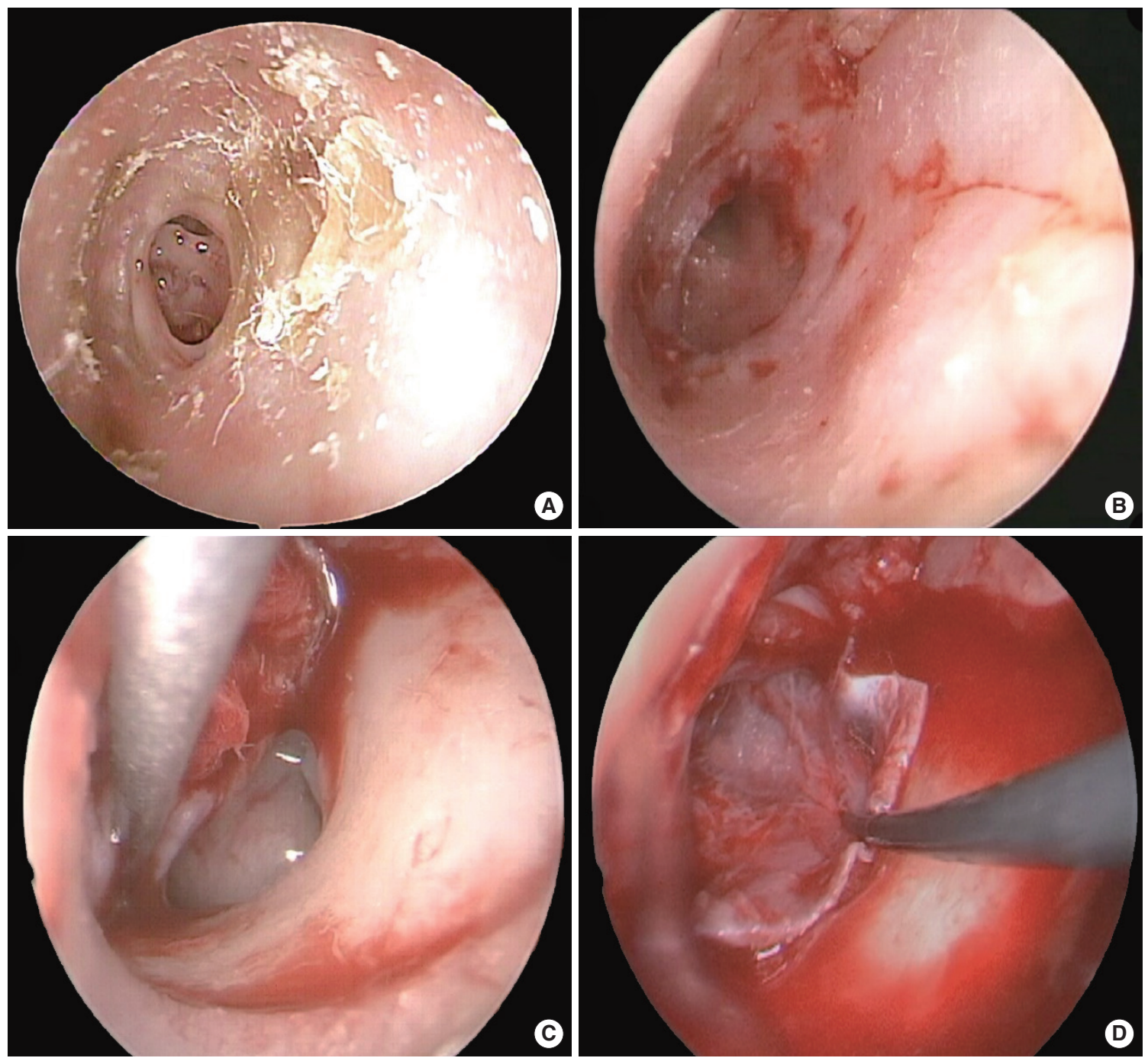

Fig. 1. Transcanal endoscopic tympanoplasty. (A) Preoperative tympanic membrane shows moderate perforation and marginal thickening. (B) Endoscopic view of the eardrum during surgery after performing marginal trimming. (C) Entering the tympanum after the elevation of a tympanomeatal flap. (D) Grafting of temporalis fascia.

\section{RESULTS}

\section{Postoperative hearing improvement}

Improvements in postoperative air conduction (AC) and air-bone gap (ABG) were compared between the two groups and no statistical significance was observed $(P>0.05)$. Both groups showed significant hearing gain after surgery $(P<0.05)$. AC gain in group 1 was $6.70 \pm 2.82 \mathrm{~dB}(P=0.045)$ and group 2 was $10.64 \pm 4.70$ $\mathrm{dB}(P<0.001)$. Improvement in $\mathrm{ABG}$ was $5.74 \pm 7.97 \mathrm{~dB}$ in group $1(P=0.009)$ and $8.97 \pm 3.51 \mathrm{~dB}$ in group $2(P<0.001)$. Hearing gain according to the type of COM was also compared. Simple COM with endoscopic surgery showed $12.19 \pm 10.58 \mathrm{~dB}$ gain in $\mathrm{AC}(P=0.009)$ and $8.54 \pm 8.80 \mathrm{~dB}$ gain in $\mathrm{ABG}$ $(P=0.018)$. In the case of adhesive otitis media with tympanoplasty using cartilage graft in all the cases, AC revealed $2.30 \pm$
Table 2. Operation methods and success rate

\begin{tabular}{lccc}
\hline Variable & $\begin{array}{c}\text { Endoscopy } \\
\text { (group 1) }\end{array}$ & $\begin{array}{c}\text { Microscopy } \\
\text { (group 2) }\end{array}$ & Total \\
\hline Approach method & & & \\
$\quad$ Transcanal & 24 & 0 & 24 \\
$\quad$ Postauricular & 0 & 15 & 15 \\
Operation method & & & \\
$\quad$ Simple tympanoplasty & 15 & 13 & 28 \\
$\quad$ Cartilage tympanoplasty & 9 & 2 & 11 \\
Anesthesia (GA:LA) & $20: 4$ & $15: 0$ & $35: 4$ \\
Anatomic success rate, $\mathrm{n}(\%)$ & $22 / 24(91.6)$ & $14 / 15(93)$ & $36 / 39(92.3)$ \\
\hline
\end{tabular}

Values are presented as number of ears unless otherwise indicated. GA, general anesthesia; LA, local anesthesia.

$12.76 \mathrm{~dB}(P>0.05)$ gain and $\mathrm{ABG}$ revealed $3.50 \pm 6.42 \mathrm{~dB}$ gain $(P>0.05)$. There were no statistically significant differences in 
hearing improvement in patients with simple COM between the two groups $(P>0.05)$ (Fig. 2).

\section{Operation time}

Operation length was calculated when the patient was present in the operation room. In group 1 with endoscopy, general anesthesia was administered to 17 patients (20 ears) and local anesthesia to four patients (four ears). In group 2 with microscopy, general anesthesia was administered to 14 patients (15 ears). In case of patients who underwent surgery for both the ears, total time was divided into half for each ear for the purpose of calculation. Mean operation time was $73.3 \pm 17.8$ minutes in group 1 and $90.3 \pm 13.8$ minutes in group 2. The endoscopic group showed statistically meaningful less operative duration $(P=0.002)$. Even for only general anesthesia cases, group 1 spent $77.0 \pm 17.1 \mathrm{~min}-$ utes in the operation room, which was less when compared to group 2 ( $P=0.018$ ) (Fig. 3).

\section{Hospitalization duration and Neodrum success rate}

The endoscopic group was hospitalized for mean 2.1 days (1-3 days) and microscopic group for 4.8 days (3-6 days). Hospitalization duration was shorter in the endoscopic group $(P<0.001)$ (Fig. 4). Typically, 22 ears in group 1 (91.6\%) and 14 ears in group 2 (93\%) did not show any reperforation more than 1 year after the surgery.
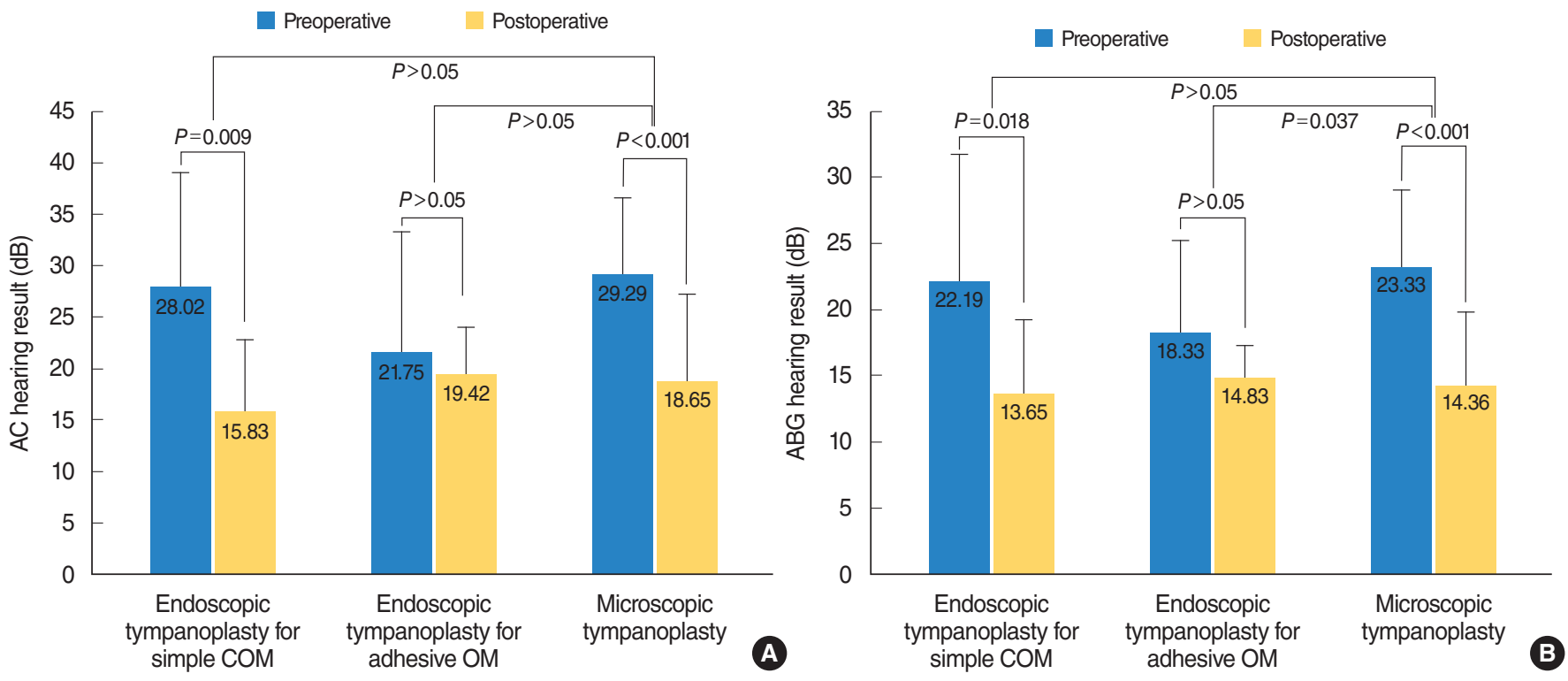

Fig. 2. Hearing results according to operation method and type of chronic otitis media (COM). (A) Air conduction (AC) hearing results. (B) Airbone gap (ABG) hearing results. All data are average values of each group.

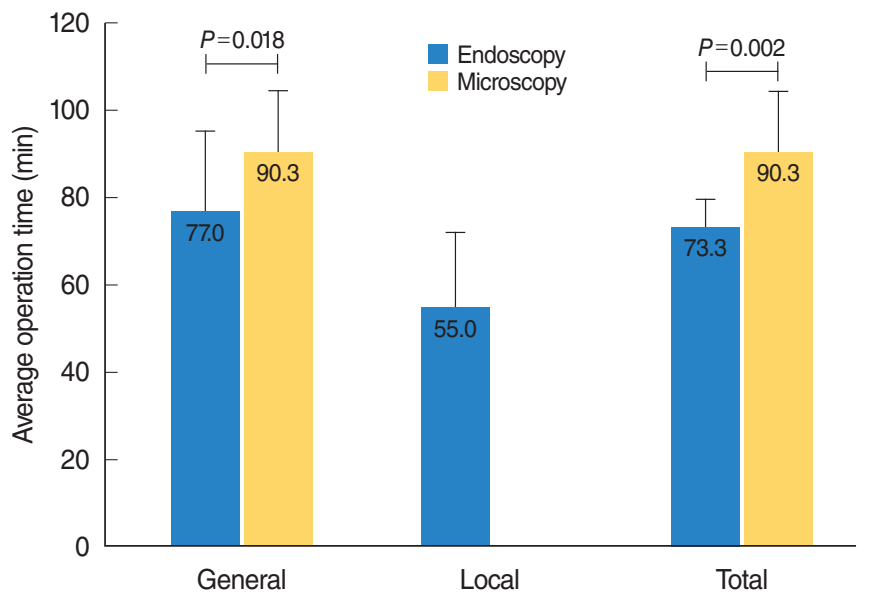

Fig. 3. Average operation time. Operation time is defined as the time that the patient has been in the operation room using nursing record.

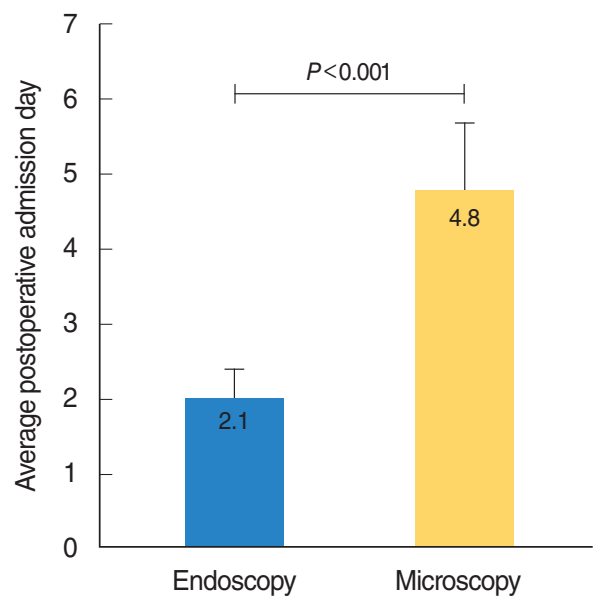

Fig. 4. Average postoperative admission days. 


\section{DISCUSSION}

The goal for the COM treatment is the elimination of otorrhea and improvement in hearing ability. These are especially important in the pediatric population due to that COM can result in life-long hearing loss $[8,9]$. In pediatric patients, retroauricular approach using microscopy is commonly incorporated as they have narrower EAC compared to the adults. The retroauricular incision is associated with increased postoperative pain and hospitalization. Thus, it is always a problem for pediatric cases.

Moreover, microscopic surgeries that are usually used until now creates difficulties in exposing specific region like the anterior portion of the tympanum in cases with bulging anterior EAC. On the other hand, the endoscope can slide directly into the narrow EAC and provide a wider overall view of the tympanum. Disease eradication and tympanic membrane reconstruction after more detailed inspection are possible compared to conventional microscopic approach $[6,7,10]$.

The advantage of the endoscopy for middle ear surgery is minimal invasiveness. Also, less damage to the normal tissue can be achieved with less operation time [11]. In the current study, no statistical difference in hearing improvement between endoscopic and microscopic groups was observed. In the case of adhesive otitis media, hearing gain was not as high as compared to the microscopic group, which could be due to the adhesive pattern of the disease instead of the operative mean. With respect to operation time, the endoscopic group showed a shortened duration as postauricular incision and reclosure were avoided. Postoperative hospitalization time was reduced in the endoscopic group owing to the absence of postauricular incision and minimizing normal tissue damage. Postauricular incision, which is commonly used in childhood COM surgery using microscope, causes postoperative pain and needs dressing of the surgical site, leading to longer hospital stay. This result coincides with the outcomes of other reports on pediatric endoscopic COM surgery [12-14].

Endoscopic tympanoplasty in the pediatric group provides a wider view compared to the conventional microscopy and creates possibilities in pediatric patients with narrow EAC. The technique demands for less soft tissue resection resulting in less operation time, less invasiveness, and less hospitalization duration. Endoscopic tympanoplasty is proposed as a good alternative to the microscopic approach in pediatric patients.

\section{CONFLICT OF INTEREST}

No potential conflict of interest relevant to this article was reported.

\section{ACKNOWLEDGMENTS}

This study was supported by a grant from Chonnam National University Hospital Biomedical Research Institute (No. BCRI 18009), Gwangju, Korea.

\section{ORCID}

Sungsu Lee https://orcid.org/0000-0002-0755-110X

Hyong-Ho Cho https://orcid.org/0000-0002-1331-4039

\section{AUTHOR CONTRIBUTIONS}

Conceptualization, Methodology, \& Project administration: HHC. Data curation, Formal analysis, \& Visualization: SL. Writing - original draft, review \& editing: all authors.

\section{REFERENCES}

1. Wullstein $\mathrm{H}$. Theory and practice of tympanoplasty. Laryngoscope. 1956 Aug;66(8):1076-93.

2. Huang TY, Ho KY, Wang LF, Chien CY, Wang HM. A comparative study of endoscopic and microscopic approach type 1 tympanoplasty for simple chronic otitis media. J Int Adv Otol. 2016 Apr;12(1): 28-31.

3. Ozgur A, Dursun E, Erdivanli OC, Coskun ZO, Terzi S, Emiroglu G, et al. Endoscopic cartilage tympanoplasty in chronic otitis media. J Laryngol Otol. 2015 Nov;129(11):1073-7.

4. Kim HC, Cho WS, Seong JY, Jeon ES, Lee SS, Cho HH. The efficacy of endoscopic exploratory tympanotomy in conductive hearing loss patients. Korean J Otorhinolaryngol-Head Neck Surg. 2017;60(1): 7-12.

5. Choi N, NohY, ParkW, Lee JJ,Yook S, Choi JE, et al. Comparison of endoscopic tympanoplasty to microscopic tympanoplasty. Clin Exp Otorhinolaryngol. 2017 Mar;10(1):44-9.

6. Badr-el-Dine M. Value of ear endoscopy in cholesteatoma surgery. Otol Neurotol. 2002 Sep;23(5):631-5.

7. Thomassin JM, Korchia D, Doris JM. Endoscopic-guided otosurgery in the prevention of residual cholesteatomas. Laryngoscope. 1993 Aug;103(8):939-43.

8. Raine CH, Singh SD. Tympanoplasty in children: a review of 114 cases. J Laryngol Otol. 1983 Mar;97(3):217-21.

9. Black JH, Hickey SA, Wormald PJ. An analysis of the results of myringoplasty in children. Int J Pediatr Otorhinolaryngol. 1995 Jan; 31(1):95-100.

10. Aoki K. Advantages of endoscopically assisted surgery for attic cholesteatoma. Diagn Ther Endosc. 2001;7(3-4):99-107.

11. KarhuketoTS, Ilomaki JH, Puhakka HJ.Tympanoscope-assisted myringoplasty. ORL J Otorhinolaryngol Relat Spec. 2001 Nov-Dec; 63(6):353-7.

12. James AL. Endoscope or microscope-guided pediatric tympanoplasty? Comparison of grafting technique and outcome. Laryngoscope. 2017 Nov;127(11):2659-64.

13. Awad OG, Hamid KA. Endoscopic type 1 tympanoplasty in pediatric patients using tragal cartilage. JAMA Otolaryngol Head Neck 
Surg. 2015 Jun;141(6):532-8.

14. Dundar R, Kulduk E, Soy FK, Aslan M, Hanci D, Muluk NB, et al.
Endoscopic versus microscopic approach to type 1 tympanoplasty in children. Int J Pediatr Otorhinolaryngol. 2014 Jul;78(7):1084-9. 